\title{
A child with pelviureteric junction obstruction in a partial quadruplex discoid pelvic kidney
}

\author{
R. Ranawaka, MBBS MS ${ }^{1}$, A.P. Dickson, Bsc MbChB FRCS (Ed) FRCS (Eng) ${ }^{2}$ \\ 1. SpR Urology, Department of Paediatric Urology, Manchester, United Kingdom \\ 2. Consultant Paediatric Surgeon and Urologist, Royal Manchester Childrens Hospital, Manchester, United Kingdom
}

Key words: Ectopic kidney; Pelviureteric junction obstruction; Imaging.

\section{Introduction}

We report an eleven year old girl who presented with recurrent UTI and was diagnosed as having an obstruction at the junction of the two moieties of a partial duplex pelvic right kidney. The left kidney was normal.

During surgery to relieve the obstruction, there were four major calyces arising from a discoid kidney uniting to form a single very dilated renal pelvis. There was a single ureter with obstruction at the pelvi-ureteric junction. The dilatation of the system resolved following AndersonHynes pyeloplasty. To our knowledge there are no similar case reports in the literature.

\section{Case report}

A pelvic right duplex kidney was diagnosed in an 11 year old girl on investigation for recurrent UTI. She was being followed up with annual ultrasound-scans. The most recent scan showed increasing dilatation of the lower moiety suggestive of obstruction. The left kidney was normal (68\% differential function). The MAG 3 scan was difficult to interpret. CT scan and magnetic resonance urogram failed to clarify the anatomy. Cystoscopy was normal. There was no vesicoureteric reflux. Retrograde pyelogram showed posteriorly directed right renal pelvis with significant hydronephrosis suggestive of obstruction.

The kidney was approached retroperitoneally via right hemi-pfannenstiel incision. On dissection, two dilated muscular tubes were identified and were thought to be "the two duplex ureters". Due to dense adhesions, access to renal pelvis was difficult. The dissection was therefore continued trans-peritoneally.

A discoid pelvic kidney containing normal looking renal tissue was found. Two more muscular tubes were arising

Correspondence: Ravibindu Ranawaka, SPR Urology Department of Paediatric Urology Royal Manchester Childrens Hospital Oxford Road,

Manchester M13 9WL

United Kingdom

E-mail: rravibindu@yahoo.com from the discoid kidney. All four tubes were identified as dissociated major calyces (Figure 1). These united to form a single dilated renal pelvis connected to a single ureter with a stenotic segment at the pelvi-ureteric junction. The distal ureter was normal (Figure 2).

Modified Anderson-Hynes dismembered pyeloplasty was performed over a $12 \mathrm{~cm}$, size $4.7 \mathrm{Ch}$ double J stent ${ }^{\circledR}$. She made an uneventful recovery. The post operative imaging showed resolution of the hydronephrosis. The double $\mathrm{J}$ stent was removed. She remains well one year after surgery.

\section{Discussion}

The lobulated foetal kidney ascends up the posterior abdominal wall to the definitive lumbar position [1]. Failure of ascent results in a pelvic kidney. This child's discoid pelvic kidney with dilated extra-renal calyces and posteriorly directed renal pelvis may have had restricted space for the ascent.

The ectopic kidney is commoner on the left side [2,3] . Most are asymptomatic [2]. They are usually hypo-plastic and $50 \%$ have a dilated system due to malrotation and vesicoureteric reflux or obstruction at the level of renal pelvis or bladder. The dissociation of the major calyces in this case may have occurred after completion of nephron-negenesis but the exact aetiology is unknown.

Discoid kidneys usually represent fusion of two pelvic kidneys [4]. This child's left kidney was normal. Therefore, probably there may have been three kidneys with two pelvic kidneys uniting to form the discoid kidney.

This surprise finding of a discoid pelvic kidney with dissociation of the major calyceal system uniting to form a dilated renal pelvis with pelvi-ureteric junction obstruction is a very interesting phenomenon.

\section{Lesson to learn}

Ectopic kidneys are subject to anatomical variations which are not always clearly defined on preoperative imaging. When operating on an ectopic kidney, the possibility of unusual anomalies or anatomy should be borne in mind. 


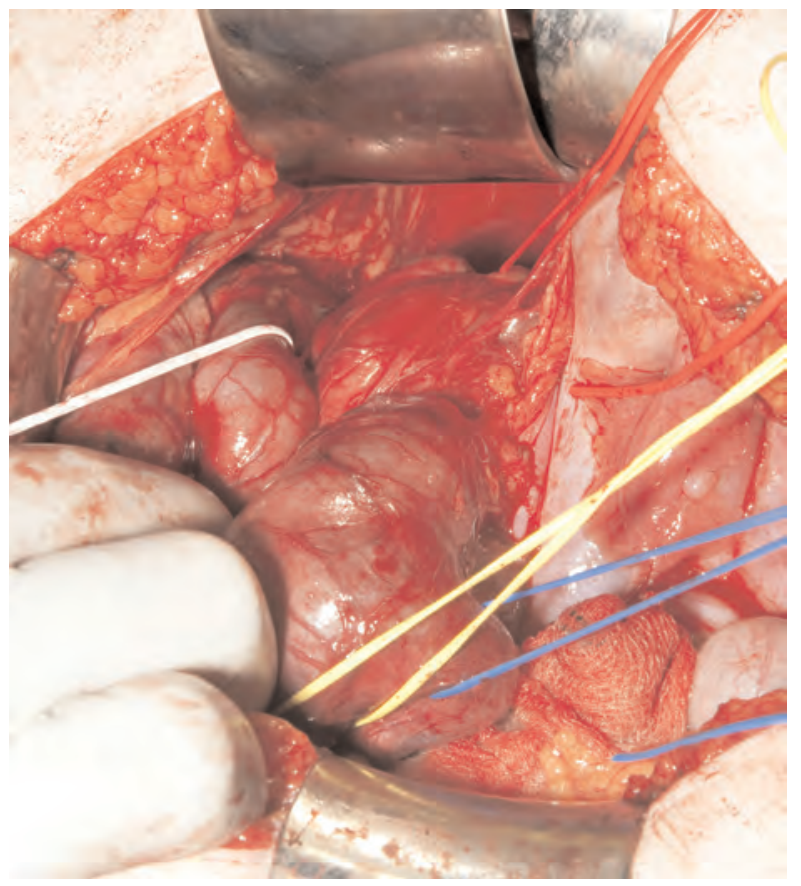

Figure 1. Per-operative photograph

Each major calyx marked by a different coloured sling.

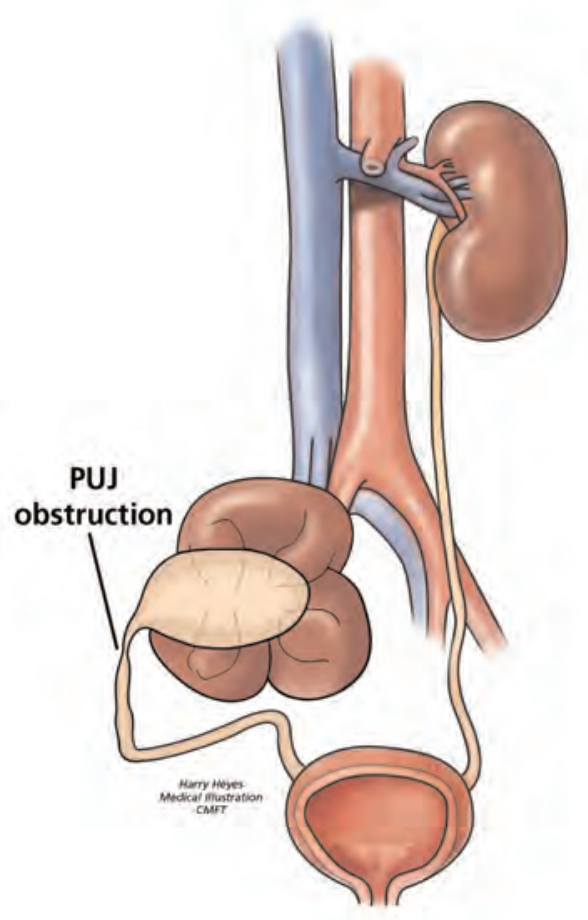

Figure 2. Line diagram of patient's anatomy

Copyright: Department of Urology, Royal Manchester Children's Hospital, United Kingdom

\section{References}

1. Thomas DFM, Duffy PG, Rickwood AMK, Essentials of Paediatric Urology. United Kingdom: Informa healthcare, 2008; 1-14

2. Payabvash S, Kajbafzadeh AM, Saeedi P, Sadeghi Z, Elmi A. et al. Application of magnetic resonance urography in diagnosis of congenital urogenital anomalies in children. Pediatric Surgical International. 2008; 24(9): 979-86.

Doi: 10.1007/s00383-008-2196-7

PMID:18668256

3. Lusch A, Koen M, Becker T, Engelhardt PF, Riccabona M. Pelvic kidney in childhood. Specific features, concomitant pathologies and useful diagnostic investigations. Der Urologe 2007; 469(2): 132-36. Doi: http://dx.doi.org/10.1007/s00120-006-1245-X PMid:17221248

4. Imamaglu T, Balkinci F, Unsal M, Ozturk MH. 'One calyx one ureter'. International Urology and Nephrology 1998; 30:429-31.

Doi: http://dx.doi.org/10.1007/BF02550221

PMID: 9821044

5. Dilli A, Ayaz ÜY, Tatar IG, Karabacak OR, Uluocak N. et al. Pancake kidney in a geriatric patient: Radiologic and scientific findings. Ankara Üniversitesi T?p Fakültesi Mecmuas? 2010; 63(4): 1-3 Doi: : 10.1501/Tipfak_000000772 